\title{
Research on Application Strategy of EPC Mode Based on BIM Technology in Cost Management of Military Readiness Engineering
}

\author{
Li Kai $^{1, *}$, Jiang Guo-ping ${ }^{2}$ \\ ${ }^{1}$ Dept. of Management Engineer and Equipment Economics,Naval Univ. of Engineering, Wuhan, 430033 China \\ ${ }^{2}$ Dept. of Management Engineer and Equipment Economics,Naval Univ. of Engineering, Wuhan, 430033 China
}

\begin{abstract}
Based on the current status of military combat readiness project cost management, this article analyzes the necessity of introducing EPC mode and BIM technology into military combat readiness project cost management and the problems existing in the application process, and proposes the EPC mode based on BIM technology in the military combat readiness project cost management The operational mechanism conception, confidentiality management, risk management and other response strategies provide reference for the reform of the military combat readiness project cost management model.
\end{abstract}

\section{Introduction}

The cost management of combat readiness engineering refers to controlling the labor, materials, machinery and other costs incurred during the implementation of the project within the approved budget in accordance with the requirements of the construction contract and under the premise of ensuring the quality and duration of the project, so as to further reduce the engineering project. Scientific management activities of construction costs ${ }^{[1]}$.

With the in-depth development of the military-civilian integration strategy, military combat readiness engineering construction projects have begun to explore the introduction of EPC management mode and BIM technology, and how to scientifically and rationally use new management models and new technologies to strengthen military combat readiness project cost management and improve military combat readiness project funding performance has become Realistic issues affecting the improvement of military combat effectiveness.

EPC (Engineering Procurement Construction), which is the "design-procurement-construction" model, also known as the turnkey project general contracting model, refers to the general contracting contract signed by the military construction department and local enterprises, which stipulates that the local enterprises will carry out project design, procurement, construction, etc. The whole process management mode of the stage. Usually a fixed total price contract model is adopted, and local enterprises are responsible for the quality, safety, cost and schedule management of the project ${ }^{[2]}$.

BIM (Building Information Modeling), or Building Information Modeling, refers to the digital expression of physical properties and functional characteristics of a construction project and the entire process of its implementation, and the general designation for the procedures and results from design, construction to operation according to this. BIM technology mainly has the following characteristics:

(1) Graphical availability. The use of BIM in design improves the design level and efficiency, which is quite different from the traditional two-dimensional drawing. BIM-based three-dimensional models can directly output two-dimensional drawings through BIM-related auxiliary software. If there is a preliminary design change, only the model needs to be adjusted, and the two-dimensional drawing can be updated in real time.

(2) Simulation. BIM's 3D technology can build architectural models, use a series of supporting analysis software to perform simulation analysis, simulate and analyze the construction site, function, performance and other related design indicators of the combat readiness project in the design phase, and use BIM's 4D technology to simulate the project schedule during the construction phase Control analysis, while using BIM's 5D technology to conduct engineering cost simulation control analysis, and use simulation technology to process business in the operation and maintenance phase.

(3) Visualization. The 3D model established by BIM technology is a three-dimensional building model that covers an informatized collection of space, appearance, information, data, etc. It has a good visualization effect. The three-dimensional effect of the proposed project after completion is directly displayed in front of the construction unit and other related aspects. It is convenient for construction units and other relevant participants to discuss and put forward repair opinions, and designers can modify on-site to improve the

* Corresponding author: Li Kai357856598@qq.com 
efficiency of design plan modification. In the construction phase, the visual characteristics of BIM technology can present the actual situation of the proposed project in advance, which can be used as a reference basis for the decision-making of each participant, which is helpful for construction disclosure. In the operation and maintenance stage, the visual characteristics of BIM technology can make reasonable spatial planning and formulate targeted emergency plans.

(4) Coordinate management. The coordinated application of BIM technology can integrate civil engineering, installation and other disciplines, and conduct reasonable collision analysis of different disciplines. It is mainly used to solve the coordination problems in the installation process of pipeline layout, structure, and internal space. Through simulation collision test, it can be found Where there are conflicts in the design of pipeline layout, structure, internal space, etc., the design plan should be optimized and adjusted in time, so as to reduce the project change visa in the later construction process and further improve the cost control ability; at the same time, the relevant process data can be real-time through the BIM information work platform The information is sent to the project participants, so that all parties can keep abreast of the progress of the project implementation, can effectively prevent the appearance of communication barriers such as information asymmetry, and further improve management efficiency.

(5) Project quantity and price calculation. The traditional budgeting cost preparation mainly includes two modules: quantity calculation and set price. On the basis of familiarity with design drawings and other engineering materials, budgeting personnel use CAD and other drawing software to establish measurement data models, and then use Glodon and other pricing software to group prices, which generally takes a long time, is inefficient, and is not accurate. Using BIM technology to build a 3D building model can be directly imported into the calculation and pricing software, which can save modeling and calculation time and further improve the accuracy of the cost.

Compared with traditional project cost management, the advantages of BIM technology in project cost management are as follows:

(1) The calculation of engineering quantity is more accurate.

(2) The accuracy and feasibility of the project design plan is stronger.

(3) The accumulation and sharing of project cost data has been realized.

(4) The timeliness of project cost data is stronger.

(5) Able to realize the dynamic control of project cost.

As shown in Figuresland 2, compared with the traditional project management model, the BIM technology platform links the owner unit, construction unit, EPC general contractor, cost consulting unit, supervision unit, design unit and other related parties through the Internet to realize project design Management, building model, procurement logistics, project schedule, cost, production operation, basic data and other related data information sharing can better realize the EPC model system management ${ }^{[3]}$.

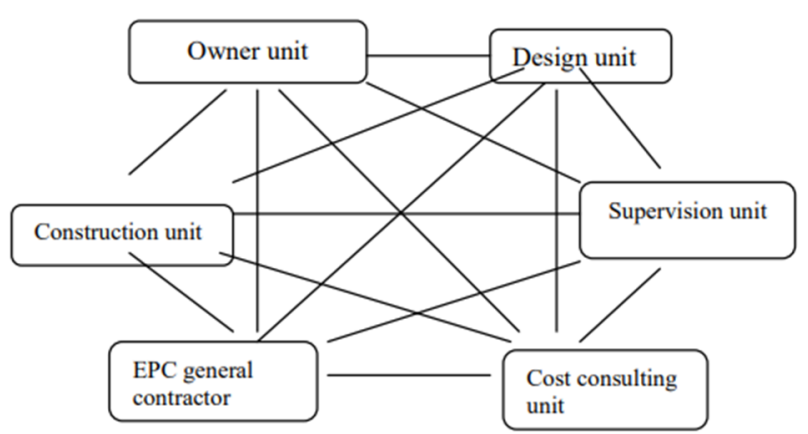

(a) Traditional way

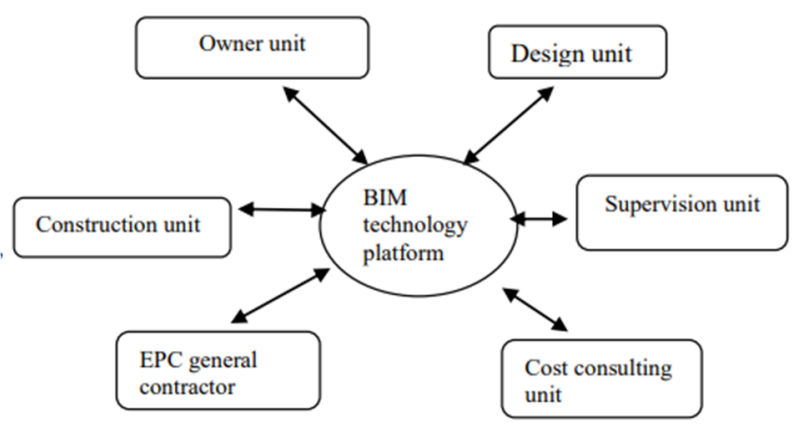

(b) BIM technology

Fig 1. Comparison of management system information transmission between traditional methods and BIM technology methods

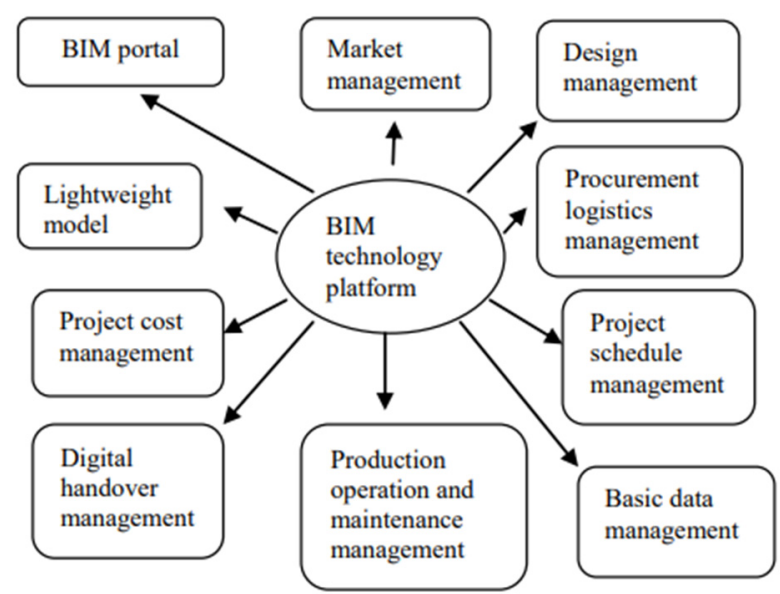

Fig 2. BIM operating platform function module

\section{The Necessity of Applying the EPC Model Based on BIM Technology to the Cost Management of Military Readiness Engineering}

In the current field of military combat readiness project management, gradually popularizing the agent construction model, beginning to explore the introduction of EPC mode and BIM technology, etc., introducing BIM technology-based EPC mode in the military combat readiness project construction, which is helpful for improving the problems in the military combat readiness project cost management, It has certain value to improve 
the performance of military combat readiness project construction funds. Compared with the traditional contracting model, the EPC general contracting model based on BIM technology has four advantages:

2.1 It can effectively overcome the contradictions of design, procurement, and construction under the traditional mode of design, procurement, and construction, and management is out of touch, forming an integrated management of design, procurement, and construction. Traditional contracting adopts the "design + construction general contracting (DB)" model to separate design, construction, procurement, etc., and implement them by different units. It is difficult to ensure the accuracy of information circulation during the handover of different units at different stages. The EPC model can avoid the traditional The problem of disconnection between design, construction, and procurement brought about by the model. For example, in the traditional contracting model, the design unit prepares the construction drawings and submits them to the construction unit for implementation. There are always many problems that cannot be constructed in the construction drawings, such as the design cuts on both sides. The force wall is too close to install the formwork, the upper reinforcement of the beam is too dense and the concrete cannot fill the inside of the beam. These problems are caused by the disconnection between design and construction. In the traditional mode, the construction party purchases equipment and constructs. When completing the civil work, it is easy to cause the problem that the final equipment cannot be installed. After adopting the EPC mode, the design unit uses BIM technology to model and conduct collision tests during the design process, fully consider the convenience of construction, and determine the equipment model in advance, so as to avoid losses and risks caused by later construction.

2.2 The responsibility subject is clear, which is conducive to the investigation of project quality responsibility and ensuring the quality responsibility bearer. In the traditional model, the survey, design, construction, and procurement are carried out separately, and the contract is signed separately. After the quality problems of the project, it is easy to cause all parties to shirk their responsibilities and arrogate each other. The EPC general contracting mode will general contract for the design, construction, and procurement content. After one unit solves the above problems, and when problems such as project quality occur, the EPC general contracting enterprise is the first responsible person, with a clear legal relationship and a clear subject of responsibility, and the owner unit's interest and damage compensation is more guaranteed.

2.3 The investment can be effectively controlled. The owner unit and the EPC general contractor sign a fixed total price and fixed duration contract, and the investment risk and construction period risk are transferred to the general contractor. Compared with the traditional domestic contract operation mode of "low winning bids, frequent visas, and high claims" usually adopted in engineering contracting based on unit price contracts, the EPC management mode can mobilize the enthusiasm and consciousness of design units to control the cost, and actively implement quota design. Further adjust and optimize the preliminary design plan, improve the quality of construction drawing design, and reduce the change visa in the later construction process of the project. The EPC management model based on BIM technology connects the design unit, owner unit, construction unit, supervision unit and other institutions through the BIM technology platform to realize data sharing. Based on the same building data model, it realizes visual operation and dynamically modifies related parameters., Real-time update of construction progress and cost-related data, so that all parties can understand the progress of the project at any time, which is conducive to the control and management of project cost.

2.4 Simplified management relationship. Under the EPC general contracting mode, in the whole process of project implementation, the owner unit only needs to communicate, coordinate and manage with the general contracting unit, which reduces the management cost of the owner unit to a certain extent, and reduces the bidding, contract negotiation and construction management of the owner unit. Coordination and other aspects can greatly reduce the management cost of the owner unit.

\section{Problems in the application of the EPC model based on BIM technology in the cost management of military combat readiness projects}

3.1 Confidentiality issues. Military preparedness projects are different from civil construction projects, and the requirements for confidentiality are very high. First of all, military combat readiness projects must not only meet combat requirements, but also meet the corresponding military technical standards and specifications. The geographic location and internal design materials of combat readiness projects often have strict confidentiality requirements. In the EPC model based on BIM technology, The general contractor has contracted the entire contents of design, procurement, construction, etc., and at the same time uses the Internet as a BIM technology platform for data sharing. There are hidden dangers of leakage and confidentiality. The issue of confidentiality needs to be resolved. Secondly, in daily work, the core of the construction project for combat readiness For confidential data, it is necessary to further study and design the work process and confidentiality system to ensure the safe and stable operation of the core confidential documents during the transmission process; finally, for the personnel involved in the confidentiality work involved in the construction of the combat readiness project, it is necessary to further improve the confidentiality of the relevant personnel in the work Security work and 
declassification management after the completion of the project. Confidentiality and security will be an important and difficult task faced by the military's combat readiness project cost management after the introduction of the EPC model based on BIM technology, and it is also a very critical task.

3.2 Risk management. The EPC model based on BIM technology is generally suitable for projects with a large investment scale, a long project cycle, and a relatively high procurement cost. In addition, the project has a large amount of preliminary work and involves many participants. These characteristics are the construction belt of the project. There is a certain potential risk. Under the EPC model, the risk of the owner unit is transferred to the general contractor. The military owner department has a low degree of participation in the project implementation process, and the control is weak. Cost management risks are still critical. For military construction units, cost management risks are mainly manifested in the following aspects. One is investment estimation risk, which is mainly due to insufficient investment estimation, insufficient project budget and low investment control efficiency; second, construction period delay risk, military combat readiness projects are general The project duration requirements are very strict. Under the management of the EPC general contractor, how the owner unit recognizes the risk of delays in the construction period is an important aspect of management; the third is the environmental impact risk, including the natural environment, such as typhoon, epidemic and other force majeure risks, as well as Market risks, such as rising prices of building materials, etc. Therefore, in the military combat readiness project, it is necessary to strengthen the management of risks, coordinate the project construction schedule, cost, and quality risk management and control, and improve the cost management efficiency of the combat readiness project.

\subsection{Lack of professional and technical personnel.} At present, there are many domestic researches on BIM technology and EPC mode, but there are relatively few cost management personnel familiar with BIM technology in the military. Researchers who are engaged in integrating cost work into multi-professional collaborative work and the application of cost management data in the whole process of engineering projects Even less, leading to the fact that the cost of the military's combat readiness project is still isolated, and there is no interconnection with new technologies such as BIM modeling software.

\section{Strategy analysis of EPC model based on BIM technology for cost management of military combat readiness engineering}

4.1 Construct the EPC mode military cost management operating mechanism based on BIM technology. As shown in Figure 3 below, from the perspective of the current military combat readiness project operation mode, an organization and management mode with the EPC general contractor as the lead unit is established, and the information integration management of the design, procurement, construction, and trial operation management links based on BIM technology is synchronized. Parallel management of the design phase, the procurement phase, and the construction phase [4].

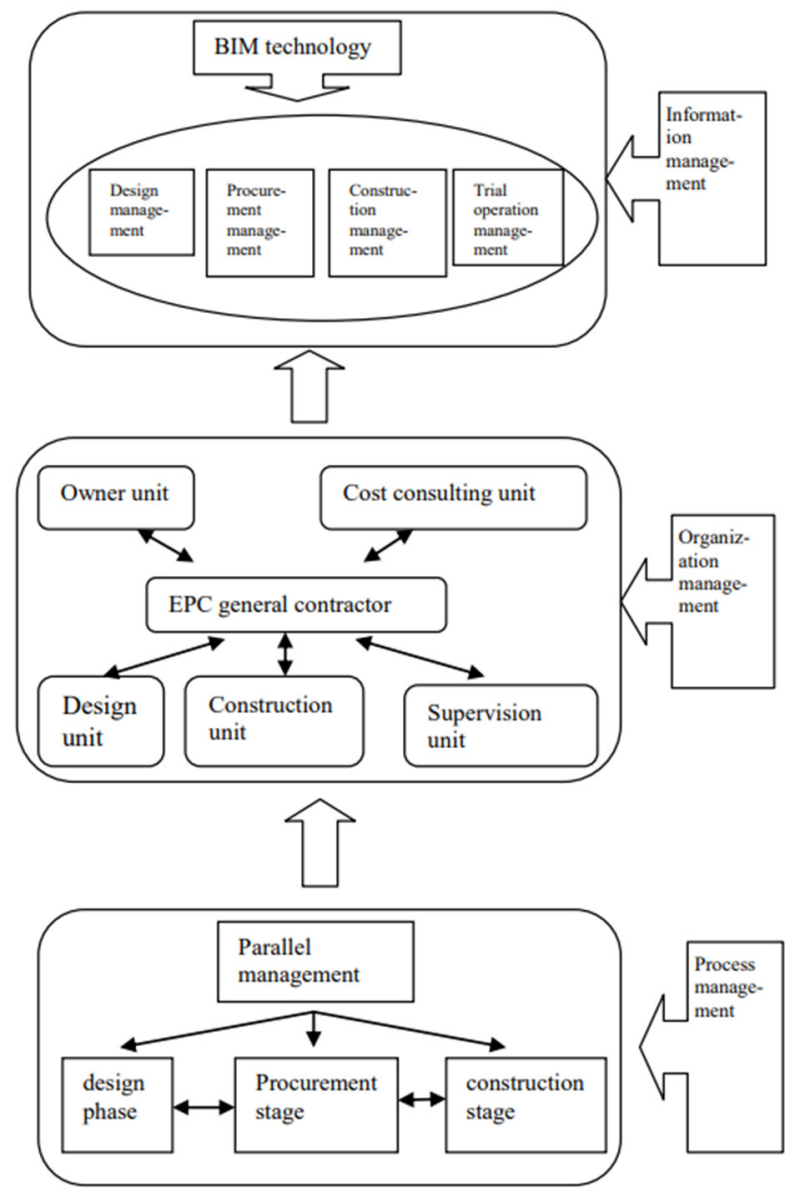

Fig 3. Conception of Military Operation Mechanism of EPC Model Based on BIM Technology

4.2 Strengthen the management of classified documents and information and the design of the confidential work system. In order to ensure the smooth implementation of the EPC model based on BIM technology, the standardization of documents and materials should be further strengthened during the construction of the combat readiness project, the relevant basic construction standard parameters should be regulated, and document examples with unified standard formats should be issued, indicating that the documents are confidential. Logo, level, etc. For confidential documents, a strict document transmission, review, filing, and destruction system must be established, and strict confidentiality procedures must be designed to prevent the leakage of military secrets. Regularly organize political and ideological education for the personnel of the military engineering construction management department, raise ideological and political awareness, 
strengthen political and confidential discipline awareness, and prevent leakage of secrets.

4.3 Strengthen the qualification review of general contracting enterprises. In the bidding stage, focus should be placed on selecting contractors with EPC general contracting experience in the military engineering contracting list and shortlist, and bidding companies are required to provide evidence of their own EPC general contracting project experience. The project members sent by the general contracting company should have rich experience in corresponding professional project management, and the organizational structure should be reasonable and efficient. Check whether they have a foreign investment background, sign a confidentiality agreement, conduct strict political review of personnel involved in the construction of combat readiness projects, and require general contractors to conduct confidentiality and safety education for their company's personnel involved in project construction to ensure that there is no risk of leakage .

4.4 Strengthen the review and management of the design plan. Relevant experts are hired to strictly review the preliminary design drawings and design estimates. In the construction drawing design review stage, use BIM technology to create the project building model, organize various units to conduct joint review, further optimize the design plan, and conduct collision tests on pipeline installation and other aspects, and import the optimized and adjusted model data into Glodon and other pricing software. Cost calculation to ensure that the project cost is controlled within the approved design specification. In order to reduce the uncertainty caused by the design, it is recommended to stipulate in the construction contract that "The EPC contractor shall be responsible for the correctness of the owner unit's requirements (including design standards and calculations)", and the EPC contractor shall be responsible for the design. Although the owner unit approves the design Documents, but does not exempt the contractor's design responsibility.

4.5 Strengthen the management of construction contracts. EPC projects generally sign a fixed total price and fixed duration contract. All the risks assumed by the contractor have been fully considered in the bid price. In the EPC contract, the owner unit transfers all the contract risks to the contractor, and both parties should confirm in the contract, And make it legal and standard. The owner unit and general contractor should carefully check whether there are omissions in the scope of the bidding project and whether the technical parameters of the relevant design requirements are accurate.

4.6 Strengthen the management of project acceptance. General contracting enterprises are required to establish awareness that military engineering quality standards are higher than local engineering, strengthen process management and control, owner units organize construction node acceptance in the process according to the plan, increase the number of acceptances according to the actual situation of the project, and link the payment of the project with the conclusion of the acceptance. In the EPC general contract, the minimum performance guarantee clause and the post-completion acceptance and inspection clauses are stipulated in detail. The minimum performance guarantee clause stipulates that "if the performance guarantees are not met, the contractor shall be liable for breach of contract, and the penalty for this part of the contract may reach $10 \%$ of the total contract price." If defects are found after the completion acceptance, the contractor shall be responsible for repairing them. If the defects or damages reach the extent that they cannot be used according to the original function (purpose), the owner unit can also claim for compensation and extend the warranty period. If the final acceptance fails, the contractor shall also The owner unit shall bear the compensation for non-performance of the contract.

4.7 Strengthen the training of EPC model and BIM technology research personnel. The owner unit can entrust colleges and universities to conduct short-term training for project management personnel to improve the project management level of BIM technology-based EPC model project cost management. Related business personnel can also participate in BIM and cost engineer qualification exams to further strengthen business theory learning .

\section{Conclusion}

Based on the current status of military combat readiness project cost management, this paper analyzes the necessity of introducing EPC mode and BIM technology into military combat readiness project cost management and the problems existing in the application process, and proposes the EPC mode based on BIM technology in the military combat readiness project cost management The operational mechanism conception, confidentiality management, risk management and other response strategies provide reference for the reform of the military combat readiness project cost management model.

\section{References}

1. Wang Xi. Thoughts on project cost management[J]. Management, 2015, 8: 143-145

2. GB/T50358-2017, Construction Project General Contracting Management Code [S] Beijing. China Construction Industry Press, 2017.

3. Li Haiwen. Research on project management of owner units under EPC mode[J]. Construction Management, 2020, 1:97-98

4. Cai Jiaru. Research on integrated management of project cost under EPC mode [D]. Chengdu, Sichuan: Xihua University, 2014:59-60 